\title{
Traducción al francés de poemas de Pere Rovira
}

Marta Giné Janer

Hace ya unos ańos, Pere Rovira me invitó a traducir 4 poemas suyos al francés. La razón se debía a una promoción de nuestro poeta, por parte de l'Institut Ramon Llull, en el "Marché de la Poésie de Paris", específicamente en su $28^{a}$ edición, en la cual la poesía catalana era la invitada de honor, y que se celebró durante la primavera del año 2010, en París, concretamente en el Hôtel de Ville.

Por aquel entonces, Pere Rovira había ya traducido, en sentido inverso, es decir, del francés al catalán, a los "très grands" Baudelaire y Ronsard. Años más tarde, Pere Rovira confirmó su agrado por la poesía francesa publicando Jardí francès. De Villon a Rimbaud ${ }^{l}$, traducciones de poemas de 25 autores pertenecientes a los cuatro siglos existentes entre los dos nombres citados.

Creo que la invitación de Pere Rovira a traducirle al francés, respondía al hecho de que acababa yo (en colaboración con Norberto Gimelfarb) de publicar dos antologías del gran poeta de Lleida, Màrius Torres, en dicha lengua².

Con Pere Rovira, que fue profesor mío antes que colega, compartimos — y seguimos compartiendo - el gusto por la poesía francesa, del siglo XIX especialmente. Por todo ello, que confiara en mí para realizar las traducciones constituyó un honor. En total, y respondiendo a lo que él, exclusivamente, seleccionó, me encargué de verter cuatro poemas: "Un pi", "Charles Baudelaire i el savis" "El rellotge de sol" y "Els vells de la platja".

1. Pere Rovira, Jardí francès. De Villon a Rimbaud, Pagès Editors (La Suda Transvària, 20), Lleida, 2016.

2. Màrius Torres, La dernière rose, édition bilingue catalan/français, Édition, introduction et traduction de Marta Giné et Norberto Gimelfarb, L’Harmattan (colección Poètes des cinq continents), París, 2008, 121 páginas.

Màrius Torres, Paroles de la nuit, édition bilingue catalan/français, Édition, introduction et traduction de Marta Giné et Norberto Gimelfarb, L'Harmattan, París, 2009, 167 páginas (edición revisada y aumentada). 
A mi entender, Rovira aprecia especialmente estos poemas suyos, que reflejan algunos de sus temas predilectos: pensar en la vida, elogiarla... Y, para ello, no olvidar el paso del tiempo y la muerte; el abismo existente, tantas veces, entre la academia, por una parte, y la sabiduría y la belleza entendidas como forma existencial. Todo ello expresado sin aflicción, con cierta ironía y también sincera melancolía en muchos casos.

Di a leer esas traducciones a un estimado amigo francés ${ }^{3}$, quien me comentó tras su lectura: "Il y a de l'âme, à Lleida". Sí, hay mucha sensibilidad y riqueza reflexiva en los poemas de Pere, que aúna un alma leridana, con la originaria de comarcas tarraconenses (algo que mi amigo no sabía).

Publicamos seguidamente esas traducciones:

\section{UN PI}

Va créixer, solitari,

a la terra arenosa d'un jardí

que s'havia de vendre.

No va ser mai el símbol d'una casa,

l'arbre d'ombra fecunda

que enraona amb els vells

i fa somiar els nens

en besavis remots de pell d'escorça.

Quan vam venir nosaltres,

el vent ja no podia fer-li mal,

$i$ les seves agulles enfilaven

la llum blanca i salada de la platja,

i estenia els seus braços de gegant

sobre un clot d'esbarzers i runa i gats,

el jardí que ningú va voler mai.

Vam construir la casa

$i$ ens vam enamorar

de l'arenal immens dels Eucaliptus

i de les hores lentes sota el pi,

sentint-lo respirar com una bèstia

cada dia més mansa i més cansada.

3. Michel Verret, filósofo, sociólogo y poeta, in memoriam. 


\section{UN PIN}

Solitaire, il grandit

Sur la terre sablonneuse d'un jardin

Qu'il fallait vendre.

Il ne fut jamais l'emblème d'une maison,

L'arbre à ombre féconde

Qui cause avec les vieux

Et fait rêver les enfants

De lointains bisaïeuls à la peau d'écorce.

Quand nous sommes venus,

Le vent ne pouvait plus lui faire de mal

Et ses aiguilles enfilaient

La lumière bleue et salée de la plage.

Et il étendait ses bras de géant

Sur un trou de buissons, de décombres et de chats,

Le jardin que nul ne voulut jamais.

Nous avons construit notre maison

Et nous nous sommes épris

De l'immense étendue de sable des Eucalyptus,

Et des heures lentes passées sous le pin,

À l'entendre respirer, tel une bête,

Chaque jour plus docile, plus fatigué. 
No va viure ni un any.

Tu deies: "el pi es mor",

i parlaves fluixet amb el seu tronc,

perquè encara esperaves que el salvés

algun miracle de la primavera.

Però no hi ha miracles, ni pels arbres:

ja era llenya seca, i el vam tallar,

i no l'hem deixat ser cap presagi de res;

només un pi, tendresa vegetal

que serà foc $i$ cendra

quan arribi l'hivern.

(La vida en plural, 1996)

\section{Charles Baudelaire i els savis}

Li regiren el cor, la cartera, les cases.

Els irriten els vicis i el dandisme,

la llista d'usurers, els insults a la mare

-tant d'amor miserable-, la sífilis, la negra

que va pintar Manet, amb un vestit de nina

i les mans de geganta -la infidel Jeanne que feia

tuf de quitrà calent quan s'escorria.

Parlen de Baudelaire com si no hagués escrit, i no amaguen que el volen intractable, retrògrad, malgastador, covard... L'autor d'un destí trist, del pobre invàlid mut dels darrers anys, el culpable, no l'home que ha fet Les Fleurs du mal, el llibre més perfecte del seu segle.

Ells no han perdut el temps rastrejant els poemes pels carrers de París.

No han convertit l'escòria i la desgràcia

en bellesa abraçada

desesperadament a les paraules.

Perdurable bellesa, més que cap capital. 
Il n'a vécu même pas un an.

Tu disais : " le pin se meurt",

Et tu parlais tout bas à son tronc,

Parce que tu attendais toujours

Quelque miracle du printemps.

Mais il n'y a pas de miracles, même pour les arbres :

Ce n'était que du bois séché, et nous l'avons coupé,

Sans lui permettre de devenir présage de rien;

Un pin, uniquement, tendresse végétale

Qui, l'hiver venant,

Deviendra feu et cendres.

\section{Charles Baudelaire et les savants}

Ils fouillent son cœur, sa bourse, ses maisons.

Irrités qu'ils sont par les vices, le dandysme,

La liste des prêteurs, les insultes à la mère

-tant d'amour misérable-, la syphilis, la Négresse

Peinte par Manet, en robe de poupée,

Aux mains de géante -l'infidèle Jeanne, qui sentait

Le goudron chaud quand elle jouissait.

Ils parlent de Baudelaire comme s'il n'avait pas écrit,

Ils ne cachent pas qu'ils le veulent intraitable, rétrograde,

Gaspilleur et poltron... L'auteur de sa triste destinée,

Le pauvre invalide muet des dernières années,

Le coupable, pas l'homme

Qui a écrit Les Fleurs du mal,

Le livre le plus parfait de son siècle.

Ils $\mathrm{n}$ n'ont pas perdu leur temps

À suivre la piste des poèmes dans les rues de Paris.

Ils n'ont pas transmué scorie et malheurs

En beauté désespéramment

Enlacée aux mots.

Beauté plus durable

Que nulle capitale. 
Ignoren com es cremen

les hores per un vers -que aquestes hores són les hores

que salven el poeta, no la posteritat.

No saben què pensava Baudelaire

dels que guarden les cendres.

(La mar de dins, 2003)

EL RELLOTGE DE SOL

Ja no fa cas ningú de la meva hora, ni de la ratlla d'ombra que poso sobre el temps, ni del meu nom, el més altiu i estrany que es pot donar a una cosa. No puc ser exacte, com es pensen ara els homes que són els seus instants; vaig amb el sol, i m'agrada parar-me cada vespre, no mesurar la nit de les estrelles, descansar en la foscor, ser rellotge dels morts. Caminant que t'atures i contemples unes xifres antigues en la pedra daurada, jo no sóc una làpida. També la teva llum s'apaga cada dia, i somies fantasmes, $\mathrm{i}$ tens un cor de terra dins del cor.

Quan siguis massa vell, que el sol t'ajudi, que escalfi la teva ombra desvalguda.

I quan mori el teu nom sobre una pedra, que algú vulgui mirar-lo amb pietat.

(La mar de dins, 2003)

\section{ElS VELLS DE LA PLATJA}

Mar de lleixiu i febre, grisa mar dels que esperen el final.

Caminen vora l'aigua amb unes cames blanques, tremoloses, i miren les onades com si miressin sang. 
Ils ignorent comment on brûle

Les heures pour un vers - que celles-ci sont les heures

Qui sauvent le poète, non la postérité.

Ils ignorent ce que pensait Baudelaire

De ceux qui veillent sur les cendres.

\section{LE CADRAN SOLAIRE}

Personne ne fait plus attention à mon heure, $\mathrm{Ni}$ à la ligne d'ombre que je trace sur le temps,

$\mathrm{Ni}$ à mon nom, le plus altier et le plus bizarre

Que l'on puisse donner à un objet. Je ne peux pas

Être exact, comme maintenant les hommes pensent

Que sont leurs instants. Je marche avec le soleil, Et j'aime à m'arrêter tous les soirs, $\mathrm{Ne}$ pas mesurer la nuit des étoiles,

Me reposer dans le noir, être l'horloge des morts.

Voyageur qui t'arrêtes et contemples

Des chiffres anciens sur la pierre dorée, Je ne suis pas une dalle. Ta lumière elle aussi

S'éteint jour après jour, et tu rêves de fantômes, Et tu as dans ton cœur un cœur en terre.

Quand tu seras trop vieux, que le soleil te réconforte, Qu'il réchauffe ton ombre abandonnée.

Et quand ton nom mourra sur une pierre,

Que quelqu'un veuille bien le regarder avec pitié.

\section{LES VIEILLARDS À LA PLAGE}

Mer d'eau de javel et de fièvre,

Mer grise de ceux qui attendent la fin.

Ils marchent près de l'eau,

De leurs jambes toutes blanches, tremblotantes,

Et regardent les vagues comme si c'était du sang. 
Mala edat de la por i de la vergonya, quan et parlen a crits o amb rialletes i ja no pots tastar el vi ni la sal.

S'ofega el dia dins d'un núvol negre i la platja esborra. Els vells se'n van, petits, pacífics, fràgils, sense veu, i semblen criatures cansades de jugar. Els mirem, allunyant-se a poc a poc.

Imaginem un pis embalsamat, un sopar sense gana, les paraules que ja no saben dir-se. No ens fan llàstima, potser perquè ens creiem que no serem com ells.

Hi penso quan travessen la finestra les primeres aranyes de la llum.

Els veig, desperts, quiets, i sento el tuf malalt dels seus llençols. En el pols del silenci, els pobres vells escolten un rellotge que només marca hores que han passat.

I penso en el meu pare, que no dorm, que no dormirà mai, i que està sol a la platja més fosca de la mar.

(La mar de dins, 2003) 
Mauvais âge que celui de la peur et de la honte,

Lorsqu'on suscite les cris ou les risettes d'autrui,

Lorsqu'on ne peut plus goûter ni le vin ni le sel.

Le jour se noie dans un sombre nuage

Et la plage s'efface. Les vieillards s'en vont,

Tout petits, calmes, fragiles, muets,

On dirait des enfants fatigués après les jeux.

Nous les voyons s'éloigner, lentement.

Nous imaginons un foyer empaillé,

Un dîner pris sans appétit,

Des mots qu'ils ne savent plus se dire.

Ils ne nous font pas pitié

Peut-être car nous croyons ne jamais devenir comme eux.

J'y pense quand ma fenêtre est traversée

Par les premières araignées de la lumière.

Je les vois insomniaques, immobiles

Et je sens la puanteur maladive de leurs draps.

Dans le pouls du silence, les vieillards

Écoutent une horloge

Qui n’indique que les heures déjà passées.

Et je pense à mon père, qui ne dort pas,

Qui ne dormira plus, et qui est tout seul

Dans la plage la plus sombre de la mer. 
Mi memoria evoca con cierta satisfacción que, tras regresar del "Marché de la poésie" de París, Pere Rovira me comentó:

-Los poemas traducidos han gustado mucho, me han dicho que sonaban muy bien.

Esta frase me recordó el proceso de la traducción: nos vimos algunas veces, con Pere, para comentar los borradores. Es sabido el esfuerzo, rigor y exigencia que conlleva toda buena escritura. Rovira quiso estar, cordialmente, al tanto de mi labor de versión. Por mi parte, intenté ser fiel a una idea que ambos compartimos: la traducción no ha de "sonar" diferente entre el original y la lengua de llegada; uno y otro han de ser poemas, poemas igualmente intensos para llegar al lector con el mismo mensaje pero también con la misma música. Hubo una palabra que nos ocasionó ciertos quebraderos: "cartera", traducido como "bourse". Al final, Pere aceptó, con la elegancia que le conocemos, mi opción. Creo que sus dudas debían venir por aquello de los "falsos amigos": bourse / borsa, tan diferente de "cartera" en catalán.

$\mathrm{Si}$, académicamente, durante bastantes cursos, yo fui la responsable de enseñar, en la UdL, a los grandes autores franceses del diecinueve que influyeron en la creación de la poesía española del siglo $\mathrm{XX}^{4}$, recuerdo que me divertía el hecho de que los estudiantes de Filología hispánica me comentaran que habían ya trabajado estos autores con Pere Rovira.

Rovira, como profesor, gustaba de ser iconoclasta, de saltarse los programas académicos establecidos para transmitir, con amenidad y encanto, a los autores que amaba, aunque no pertenecieran a la literatura hispánica. En mi caso concreto como estudiante, Pere Rovira se "saltó" algún autor del programa para descubrirnos a Gabriel Ferrater, en aquellos momentos, poco conocido.

En mi hoy académico y personal solo puedo agradecer a Rovira su lectura de Ferrater, un autor que he seguido leyendo y releyendo, y un verso del cual escogí para poner título al primer libro de creación que mi transcurso vital me ha llevado a escribir 5 .

4. Entre otros a Baudelaire y a Gautier: ambos están muy presentes en las traducciones mencionadas. Los dos autores escribieron sendos poemas a un reloj. "El rellotge de sol" de Rovira es una oportuna continuación de la temática.

5. Marta Giné Janer, I anem de fred en fred, sense pensar-hi, Edicions Saragossa, Barcelona, 2016, Premi "Paraules a Icària", secció "Ritmes", any 2016. 